\title{
Self-rated health and objective health status as predictors of all-cause mortality among older people: a prospective study with a 5-, 10-, and 27-year follow-up
}

Marit Wuorela ${ }^{1,2^{*}}$, Sirkku Lavonius ${ }^{1,3}$, Marika Salminen ${ }^{2,4}$, Tero Vahlberg ${ }^{5}$, Matti Viitanen ${ }^{1,6}$ and Laura Viikari ${ }^{1,2}$

\begin{abstract}
Background: Despite a non-specific nature of self-rated health $(\mathrm{SRH})$, it seems to be a strong predictor of mortality. The aim of this study is to assess the association of SRH and objective health status $(\mathrm{OH})$ with all-cause mortality in 70-year-old community-dwelling older people in Finland.

Methods: A prospective study with 5-, 10- and 27-year follow-ups. SRH $(n=1008)$ was assessed with a single question and $\mathrm{OH}(n=962)$ by the Rockwood's Frailty Index $(\mathrm{FI})$. To assess the association of SRH and OH with mortality, Cox regression model was used.

Results: Of the 1008 participants, 138 (13.7\%), 319 (31.6\%), and 932 deceased (86.3\%) during the 5-, 10- and 27-year follow-ups, respectively. In unadjusted models, subjects with poor SRH had almost eightfold risk for mortality compared to those with good SRH during the 5-year follow-up; among those with poor $\mathrm{OH}$, the risk was fourfold compared to those with good $\mathrm{OH}$. In the 10-year-follow up, both poor SRH and poor OH predicted about fourfold risk for mortality compared to those with good health. During the 27-year follow-up, $\mathrm{OH}$ was a stronger predictor of mortality than SRH. Poor SRH, compared to good SRH, showed 95\% sensitivity and 34\% specificity for 5-year mortality; corresponding figures for $\mathrm{OH}$ were 54 and 80\%, respectively.

Conclusions: Single-item SRH seems to be able to capture almost the same as $\mathrm{OH}$ in predicting a short-term (less than 10 years) mortality risk among older adults in clinical settings. The use of SHR may also enhance the focus on patient-centered care.
\end{abstract}

Keywords: Frailty, Mortality, Objective health, Older people, Self-rated health

\section{Background}

Self-rated health (SRH) is a subjective indicator of health status that integrates biological, mental, social and functional aspects of a person, including individual and cultural beliefs and health behaviors [1]. Despite seemingly

\footnotetext{
* Correspondence: maarit.wuorela@turku.fi

${ }^{1}$ Faculty of Medicine, Department of Geriatrics, University of Turku, Turku City Hospital, Kunnallissairaalantie 20, Fl-20700 Turku, Finland

${ }^{2}$ City of Turku, Welfare Division, Turku, Finland

Full list of author information is available at the end of the article
}

non-specific nature of SRH, it has shown to be an unusually strong predictor of mortality $[2,3]$. The predictive value of SRH, in part, reflects its lack of definition. A lot of objective information is included in the selfassessment of health, probably even more than is usually possible to include in a survey instrument or even to gather in a busy clinical settings [4]. Nevertheless, single-item self-reported scales, such as SRH, is often overlooked by clinicians because they assume that it is

C The Author(s). 2020 Open Access This article is licensed under a Creative Commons Attribution 4.0 International License, which permits use, sharing, adaptation, distribution and reproduction in any medium or format, as long as you give appropriate credit to the original author(s) and the source, provide a link to the Creative Commons licence, and indicate if changes were made. The images or other third party material in this article are included in the article's Creative Commons licence, unless indicated otherwise in a credit line to the material. If material is not included in the article's Creative Commons licence and your intended use is not permitted by statutory regulation or exceeds the permitted use, you will need to obtain permission directly from the copyright holder. To view a copy of this licence, visit http://creativecommons.org/licenses/by/4.0/. The Creative Commons Public Domain Dedication waiver (http://creativecommons.org/publicdomain/zero/1.0/) applies to the data made available in this article, unless otherwise stated in a credit line to the data. 
less reliable and more sensitive to contextual effects than objectively assessed health status [5-7].

In the earlier meta-analysis of 22 studies, the duration of follow-ups ranged from 15 months to 25.1 year. The association between general SRH and mortality was similar for studies with greater than and for those with less than 5 years maximum follow-up. In 10 studies with follow-ups from 15 months to 12 years, participants were 65 years or older. However, no subgroups analyses by age were conducted [2]. Among older people, long-term predictive value of SHR has found to be poorer than that of short-term [8-11].

In this study, our main interest was to clarify whether a single-item SRH is valuable tool for risk assessment of older adults in busy clinical settings. Therefore, we analysed the association of SRH and objective health status $(\mathrm{OH})$ with all-cause mortality in 70-year-old community-dwelling older people in Finland during the 5-, 10- and 27-year follow-up.

\section{Methods}

\section{Study participants}

The study population of this prospective follow-up study consisted of all 70-year-old community-dwelling older adults of the city of Turku (The Turku Elderly Study) in Southwestern Finland, who were born in 1920. Data were collected in 1990-1991 by using postal questionnaires, interviews and clinical examinations. The protocol of data collection and flow chart are described in detail previously [12]. One thousand thirty-two (83\%) participants completed the whole study protocol, but those with missing data of SRH $(n=24)$ were excluded, leaving 1008 participants for this study. They were followed up for 27 years for all-cause mortality.

\section{Data collection}

SRH was measured by using a single question "in general, how would you rate your health" with reply alternatives: 1 . good, 2. rather good, 3. poor, and 4. very poor. Responses "poor" and "very poor" were combined because of low number of responses in category "very poor" $(n=31)$, creating a three-category SRH variable: 1 . good, 2. rather good, and 3. poor.

Rockwood's comprehensive and multidimensional FI, which characterizes the whole health of individual [13], was used as a measure of objective health status $(\mathrm{OH})$. FI consists of at least 30 deficits, such as symptoms, signs, disabilities, diagnoses, and laboratory measurements, which are readily available in survey or clinical data $[14,15]$. In this study, FI consisted of 36 items described in Additional file 1. For any individual, FI was calculated as the number of deficits divided by the number of items considered [15]. In this study, $\mathrm{OH}$ was classified according to the level of FI $[16,17]$ as follows: 1 . good (FI $\leq 0.08$, robust), 2 . moderate (FI $0.09-0.24$, prefrail), and 3. poor (FI $\geq 0.25$, frail) [18].

Data of potential confounding factors were collected by using postal questionnaires and interviews. Sociodemographic variables used were age, gender, living circumstances (1. living with someone, 2 . living alone), and education (1. $\leq 8$ years, 2 . $\geq 9$ years). Need for help was assessed with three variables (yes/no): need for daily help, having help from a relative at least once a week, and having someone who helps when needed.

Cognitive function was measured by Mini-Mental State Examination [19]. Cognitive impairment was defined as a score lower than $27[20,21]$. Charlson comorbidity index $(1.0-1,2 . \geq 2)[22,23]$ was used to record presence of chronic comorbid disease.

Psychosocial status was measured with questions concerning feelings of depression (1. never or seldom, 2. sometimes, often or always), loneliness (1. never or seldom, 2. sometimes, often or always), and life satisfaction (1. yes, 2. no).

Weight and height were measured, and body mass index (BMI), measured as kilograms per square meter, was calculated. Weight change during the past 3 years was assessed as follows: 1 . increased, 2 . no change, and 3 . decreased. Health behavior was measured with questions concerning smoking (1. never, 2. stopper or smoking) and having daily outdoor activities (1. yes, 2. no). Physical functioning was assessed with difficulties in walking $500 \mathrm{~m}$ (1. no, 2. yes) and number of falls during the previous 12 months (1. no falls, 2 . 1-2 falls, $3 . \geq 3$ falls).

The study Data from all participants who died before January 2017 were obtained from the official Finnish Cause of Death Register using unique personal identification numbers.

\section{Statistical analyses}

Baseline differences by SRH were analyzed using the Chi-squared test and Fisher's exact test. Hazard ratios (HRs) and their 95\% confidence intervals (CI) for allcause mortality were calculated using Cox proportional hazard models. Proportional hazards assumption was tested by using Martingale residuals. The follow-up periods were calculated from baseline measurements to the end of the follow-ups of 5-, 10- and 27-year or to the death of the person.

Firstly, unadjusted Cox regression analyses were conducted for SRH and OH. Secondly, Cox regression analyses for $\mathrm{OH}$ was adjusted for gender and SRH for those possible confounding factors which were significantly associated with higher mortality risk at the follow-ups of 5-, 10- and 27- year and which did not have high between-correlation. The interaction between genders was included in Cox regression models. Thirdly, 
interaction between $\mathrm{OH}$ and SRH was analyzed, genders together and separately, in order to examine whether SRH gives any extra value in evaluation of mortality risk by $\mathrm{OH}$.

$P$-values less than 0.05 were considered statistically significant. All statistical analyses were performed by using SAS System for Windows, version 9.4 (SAS Institute Inc., Cary, NC, USA).

\section{Results}

\section{Baseline characteristics}

Overall, 10.2, 63.9, 25.9\% of the participants reported having good, rather good, or poor SRH, respectively. Table 1 shows the baseline characteristics of the participants by SRH. Ninety percent of the participants with good SRH also had good $\mathrm{OH}$; participants with poor $\mathrm{SRH}, 7,49$, and $44 \%$ were categorized as having good, moderate, or poor $\mathrm{OH}$, respectively $(p<0.001)$ (Table 2$)$. $\mathrm{SRH}$ was highly correlated with $\mathrm{OH}$ was (Spearman's correlation coefficient $0.57, p<0.001$ ).

\section{Self-rated health and objective health status and risk of} mortality

Of the total of 1008 participants, 138 (13.7\%), 319 (31.6\%), and $932(86.3 \%)$ deceased during the 5-, 10and 27-year follow-ups, respectively. According to both unadjusted and adjusted Cox proportional hazard models, poor SRH and both moderate and poor $\mathrm{OH}$ were associated with significantly higher mortality risk during the 5-, 10- and 27-year follow-ups (Tables 3 and 4). According to clinically more interesting unadjusted models, poor SRH was a stronger predictor of short-term (5- and 10-year follow-up periods) mortality than $\mathrm{OH}$. Figure 1 shows the KaplanMeier curves of unadjusted analyses of SRH and $\mathrm{OH}$ for all-cause mortality during the total of 27-year follow-up. However, after adjustment of analyses of SRH with multiple confounding factors significantly associated with mortality, gender-adjusted $\mathrm{OH}$ slightly stronger predicted mortality than SRH in 5-, 10-, and 27-year follow-up.

Table 1 Baseline characteristics of the community-dwelling 70-year-old people $(n=1008)$ by self-rated health

\begin{tabular}{|c|c|c|c|c|}
\hline & $\begin{array}{l}\text { Good }(n=103) \\
\mathrm{n}(\%)\end{array}$ & $\begin{array}{l}\text { Rather good } \\
(n=644) \\
n(\%)\end{array}$ & $\begin{array}{l}\text { Poor }(n=261) \\
n(\%)\end{array}$ & $P$-value \\
\hline Women & $67(65)$ & $437(68)$ & $142(54)$ & $<.001$ \\
\hline Living alone & $39(38)$ & $283(44)$ & $97(37)$ & .127 \\
\hline Education $\geq 9$ years & $37(38)$ & $114(18)$ & $34(13)$ & $<.001$ \\
\hline Need for daily help & $0(0)$ & $15(2)$ & $61(24)$ & $<.001$ \\
\hline Help from a relative at least once a week & $19(19)$ & $142(23)$ & $111(43)$ & $<.001$ \\
\hline Having someone who helps when needed & $86(85)$ & $509(81)$ & $211(81)$ & \\
\hline Mini-Mental State Examination $<27$ & $26(25)$ & $217(34)$ & $104(40)$ & .018 \\
\hline Charlson's comorbity index $\geq 2$ & $57(58)$ & $373(60)$ & $175(71)$ & .005 \\
\hline Feelings of depression at least sometimes & $16(16)$ & $178(28)$ & $131(51)$ & $<.001$ \\
\hline Feelings of loneliness at least sometimes & $6(6)$ & $152(24)$ & $102(40)$ & $<.001$ \\
\hline Satisfaction with life & $98(98)$ & $613(97)$ & $224(88)$ & $<.001$ \\
\hline Body mass index, $\mathrm{kg} / \mathrm{m}^{2}$ & & & & .257 \\
\hline$<25$ & $43(48)$ & $189(37)$ & $57(35)$ & \\
\hline $25-29.9$ & $34(38)$ & $241(47)$ & $73(45)$ & \\
\hline$\geq 30$ & $13(14)$ & $86(17)$ & $32(20)$ & \\
\hline Weight change during the past 3 years & & & & $<.001$ \\
\hline Increased & $18(18)$ & $1616(25)$ & $75(29)$ & \\
\hline No change & $72(71)$ & $374(59)$ & $122(47)$ & \\
\hline Decreased & $12(12)$ & $96(15)$ & $60(23)$ & \\
\hline Smoking & & & & .041 \\
\hline Has never smoked & $60(58)$ & $381(60)$ & $133(51)$ & \\
\hline Has stopped or is still smoking & $43(42)$ & $256(40)$ & $126(49)$ & \\
\hline Having daily outdoor activities & $100(97)$ & $624(98)$ & $221(86)$ & $<.001$ \\
\hline Difficulties in walking $500 \mathrm{~m}$ & $5(5)$ & $71(11)$ & $116(45)$ & $<.001$ \\
\hline Three or more falls during the previous 12 months & $3(3)$ & 18 (3) & $27(10)$ & $<.001$ \\
\hline
\end{tabular}


Table 2 Cross-classification of self-rated health by objective health status among community-dwelling 70-year-old people $(n=943)$

\begin{tabular}{|c|c|c|c|c|}
\hline & \multicolumn{3}{|c|}{ Self-rated health } & \multirow{2}{*}{$\begin{array}{l}P \text { - } \\
\text { value }\end{array}$} \\
\hline & $\begin{array}{l}\text { Good }(n=97) \\
n(\%)\end{array}$ & $\begin{array}{l}\text { Rather good }(n=604) \\
n(\%)\end{array}$ & $\begin{array}{l}\text { Poor }(n=242) \\
n(\%)\end{array}$ & \\
\hline Objective health status & & & & $<.001$ \\
\hline Good & $87(90)$ & $344(57)$ & $17(7)$ & \\
\hline Moderate & $10(10)$ & $226(37)$ & $118(49)$ & \\
\hline Poor & $0(0)$ & $34(6)$ & $107(44)$ & \\
\hline
\end{tabular}

The association of SRH and mortality did not significantly differ between men and women at any given follow-up; both moderate $(p=0.047)$ and poor $\mathrm{OH}(p=$ $0.015)$ predicted significantly higher mortality risk among men (HR 1.85 [95\% CI 1.46-2.34] for moderate $\mathrm{OH} ; 3.59$ [2.59-4.97] for poor $\mathrm{OH})$ than women $(1.45$ [1.21-1.73]; 2.51 [1.97-3.21], respectively) during the 27-year follow-up.

We also analyzed interaction between $\mathrm{OH}$ and $\mathrm{SRH}$ in order to examine whether SRH gives any extra value in evaluation of mortality risk by $\mathrm{OH}$. Analyses were conducted genders together and separately. No statistically significant interactions were found at any given follow-up.

\section{Sensitivity and specificity of self-rated health and objective health status for 5-year mortality}

We also analyzed sensitivity and specificity of poor SRH and poor $\mathrm{OH}$ for 5-year mortality. When poor $\mathrm{SRH}$ was compared to good SRH, sensitivity and specificity were 95 and $34 \%$, respectively, whereas in comparison of poor $\mathrm{SRH}$ with rather good or good SRH, sensitivity and specificity were 51 and 78\%, respectively. Poor $\mathrm{OH}$ compared to good $\mathrm{OH}$ showed $53 \%$ sensitivity and $80 \%$ specificity. Corresponding figures for poor $\mathrm{OH}$ compared to moderate or good $\mathrm{OH}$ were 33 and $87 \%$, respectively.

\section{Discussion}

This study aimed to analyze the association of SRH and $\mathrm{OH}$ with all-cause mortality, showed that SRH performs well in comparison to $\mathrm{OH}$. According to our results, in (clinically interesting) unadjusted models, poor SRH predicted mortality stronger than having a moderate or poor $\mathrm{OH}$ in 5- and 10-year follow-ups. After adjustments of SRH with multiple variables, which were significantly associated with higher mortality risk at given follow-ups, the association of poor SRH with mortality was still almost as strong as the association of poor $\mathrm{OH}$ with mortality in 10-year follow-up. In 27-year followup, although the predictive value of $\mathrm{OH}$ was higher than that of SRH poor self-rated health still predicted higher mortality risk. In consistence with our results, several earlier studies have shown that poor SRH is associated with higher mortality risk [2, 6, 24-26] but long-term predictive value of SHR has found to be poorer than that of short-term among older adults [8-11]. Anyhow, it seems that the subjective feeling of one's health may be able to capture the same if not more than comprehensive, multidimensional and time-consuming objective assessment of health for prediction of mortality risk [27]. According to Jylhä [3], good SRH is no guarantee of true health, but poor SRH certainly needs further attention. However, SRH did not give any extra value in evaluation of mortality risk by $\mathrm{OH}$ at any given follow-up.

Single-item self-reported scales, such as SRH, are often overlooked as they are perceived as less reliable and more sensitive to contextual effects [5-7]. However, SRH is a generally reliable measure, and at the population level, sufficiently stable [28]. In

Table 3 Unadjusted hazard ratios (HR) and their 95\% confidence intervals (CI) (in parentheses) of self-rated health and objective health status for all-cause mortality among home-dwelling 70-year-old people during the 5-, 10- and 27-year follow-up

\begin{tabular}{|c|c|c|c|c|c|c|c|}
\hline \multirow[b]{2}{*}{ Self-rated health $(n=1008)$} & \multirow[b]{2}{*}{$n(\%)$} & \multicolumn{2}{|l|}{ 5-year follow-up } & \multicolumn{2}{|l|}{ 10-year follow-up } & \multicolumn{2}{|l|}{ 27-year follow-up } \\
\hline & & $\mathrm{HR}(95 \% \mathrm{Cl})$ & $P$-value & HR $(95 \% \mathrm{Cl})$ & $P$-value & HR $(95 \% \mathrm{Cl})$ & $P$-value \\
\hline Good & $103(10)$ & 1 & & 1 & & 1 & \\
\hline Rather good & $644(64)$ & $2.60(0.95-7.13)$ & .064 & $1.79(1.07-2.99)$ & .026 & $1.23(0.99-1.53)$ & .067 \\
\hline Poor & $261(26)$ & $7.89(2.88-21.61)$ & $<.001$ & $4.59(2.73-7.70)$ & $<.001$ & $2.01(1.58-2.56)$ & $<.001$ \\
\hline \multicolumn{8}{|c|}{ Objective health status ( $n=962$ ) } \\
\hline Good & $451(47)$ & 1 & & 1 & & 1 & \\
\hline Moderate & $363(38)$ & $1.60(1.05-2.45)$ & $<.001$ & $1.93(1.48-2.52)$ & $<.001$ & $1.50(1.30-1.74)$ & $<.001$ \\
\hline Poor & $148(15)$ & $3.98(2.57-6.16)$ & .030 & $3.85(2.86-5.18)$ & $<.001$ & $2.57(2.12-3.12)$ & $<.001$ \\
\hline
\end{tabular}


Table 4 Adjusted hazard ratios (HR) and their 95\% confidence intervals (Cl) (in parentheses) of self-rated health and objective health status for all-cause mortality among home-dwelling 70-year-old people during the 5-, 10- and 27-year follow-up

\begin{tabular}{|c|c|c|c|c|c|c|c|}
\hline \multirow[b]{2}{*}{ Self-rated health $(n=1008)$} & \multirow[b]{2}{*}{$n(\%)$} & \multicolumn{2}{|l|}{ 5-year follow-up } & \multicolumn{2}{|l|}{ 10-year follow-up } & \multicolumn{2}{|l|}{ 27-year follow-up } \\
\hline & & HR $(95 \% \mathrm{Cl})$ & $P$-value & HR $(95 \% \mathrm{Cl})$ & $P$-value & $\mathrm{HR}(95 \% \mathrm{Cl})$ & $P$-value \\
\hline Good & $103(10)$ & $1^{\text {a }}$ & & 1 & & 1 & \\
\hline Rather good & $644(64)$ & & & $2.29(1.24-4.23)^{c}$ & .009 & $1.19(0.94-1.51)^{d}$ & .143 \\
\hline Poor & $261(26)$ & $2.17(1.42-3.31)^{\dagger}$ & $<.001^{b}$ & $4.08(2.14-7.77)^{\ddagger}$ & $<.001$ & $1.62(1.23-2.13)^{d}$ & $<.001$ \\
\hline \multicolumn{8}{|c|}{ Objective health status ( $n=962)$} \\
\hline Good & $451(47)$ & 1 & & 1 & & 1 & \\
\hline Moderate & $363(38)$ & $1.62(1.06-2.48)^{\mathrm{e}}$ & .027 & $1.99(1.53-2.60)^{\mathrm{e}}$ & $<.001$ & $1.62(1.40-1.87)^{\mathrm{e}}$ & $<.001$ \\
\hline Poor & $148(15)$ & $4.13(2.67-6.40)^{\mathrm{e}}$ & $<.001$ & $4.20(3.12-5.66)^{\mathrm{e}}$ & $<.001$ & $2.91(2.40-3.54)^{\mathrm{e}}$ & $<.001$ \\
\hline
\end{tabular}

"Categories "rather good" and "good" are combined for statistical analyses because of the lack of deceased among subjects with a good self-rated health ${ }^{\mathrm{b}}$ Adjusted for variables associated with 5-year mortality: gender, education, need for daily help, having someone (relative) who helps when needed, smoking, weight change, ability to walk $500 \mathrm{~m}$, comorbidity, and life satisfaction, $(n=882)$

'Adjusted for variables associated with 10-year mortality: gender, education, need for daily help, having someone (relative) who helps when needed, smoking, weight change, ability to walk $500 \mathrm{~m}$, feelings of depression, and life satisfaction, $(n=910)$

${ }^{\mathrm{d}}$ Adjusted for variables associated with 27-year mortality: gender, need for daily help, having someone (relative) who helps when needed, smoking, weight change, ability to walk $500 \mathrm{~m}$, falls, feeling of depression, and life satisfaction, $(n=908)$

${ }^{\mathrm{e}}$ Adjusted for gender

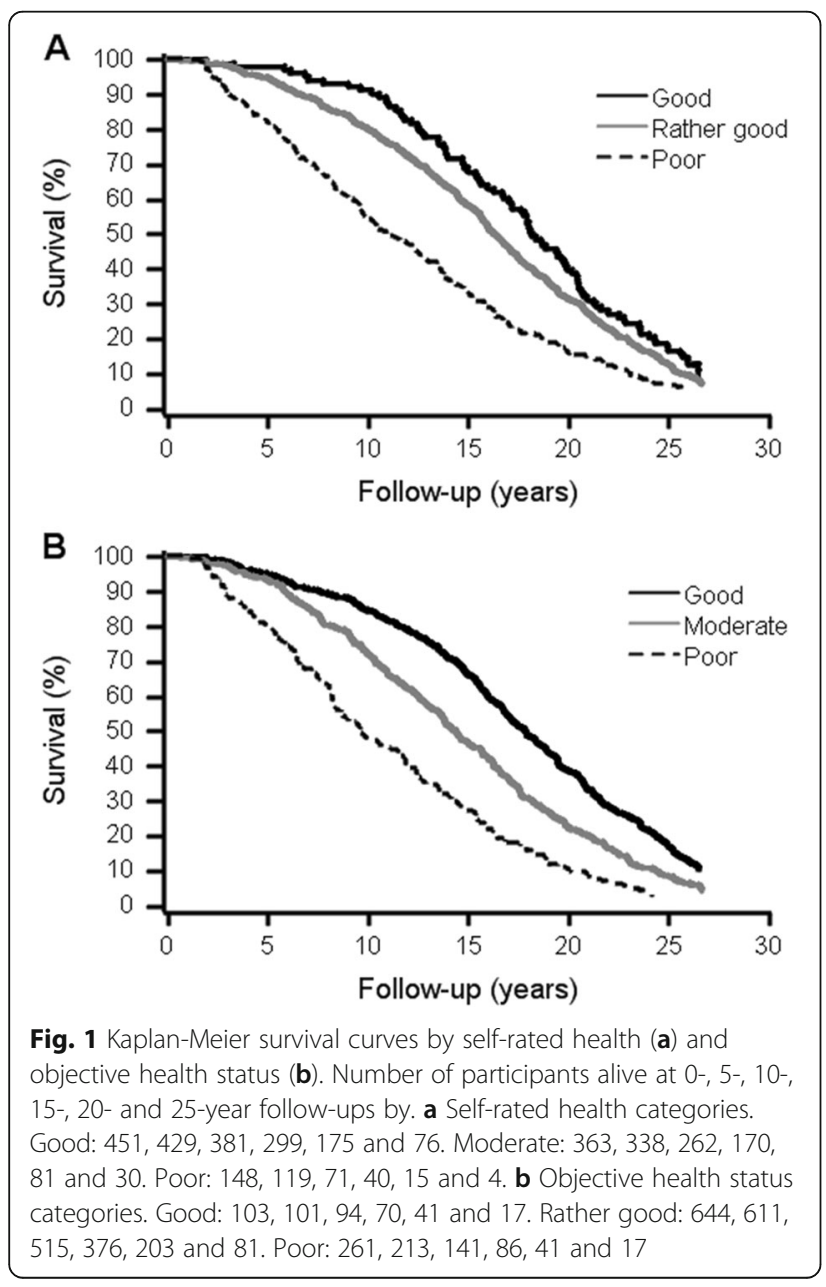

clinical settings, SRH can also serve as a screening tool for patients' health status and to enhance patient-centered care by allowing the patient to express a point of view genuinely his or her own [3]. This supports the use of SRH as a simple measure both in survey and clinical settings to identify vulnerable older adults $[26,28]$. There is also evidence that the validity of SRH is increasing. This is probably because individuals are including more objective information in their self-assessment of health. It is also possible that individuals are considering more mortality-related conditions than they did in the past. Therefore, SRH should not be overlooked when it comes to understanding individuals' health [24].

The findings of previous studies have been contradictory in relation to gender differences in the association of SRH and mortality [10]. In our study, the predictive value of SRH did not significantly differ between men and women at any given follow-up. Having moderate or poor $\mathrm{OH}$, instead, predicted significantly higher mortality risk among men than women in 27-year follow-up. In our study, comprehensive and multidimensional FI, which characterizes the whole health of individual, we used as a measure of $\mathrm{OH}$. According to the results of a meta-analysis, women had higher FI scores than men but lower mortality rate at any given level of frailty or age. This suggests that women tolerate frailty better than men [29].

The strengths of this study were a large sample size with a high response rate and a long follow-up period. SRH was assessed by a global SHR question, which has found to be more accurate for prediction of mortality in old age than for example, comparative question [30]. In our study, no time-dependent covariates [9] were used; proportional hazard assumption of baseline SRH and 
$\mathrm{OH}$ were tested by using Martingale residuals. Analyses for SRH were also adjusted for multiple confounding factors that were significantly associated with higher mortality risk at every given follow-up. It is possible, that this has led to over-adjustment, since factors, such as gender, education, need for daily help, ability to walk $500 \mathrm{~m}$, feelings of depression and life satisfaction, may mediate the association between SRH and mortality.

\section{Conclusions}

Findings of our study provide additional evidence supporting the value of incorporating a single-item measure of SRH into risk assessment of older adults in busy clinical settings. Routinely collecting SRH may also enhance the focus on patient-centered care.

\section{Supplementary information}

Supplementary information accompanies this paper at https://doi.org/10. 1186/s12877-020-01516-9.

Additional file 1. Variables used in the assessment of objective health status

\section{Abbreviations}

BMI: Body mass index; Cl: Confidence intervals; Fl: Frailty index; HR: Hazard ratio; $\mathrm{OH}$ : Objective health status; $\mathrm{SRH}$ : Self-rated health

\section{Acknowledgements}

We would like to show our gratitude to the research nurse Sanna Himanen who participated in the data collection as well as to the data manager Teemu Kemppainen for his help in statistical analyses.

\section{Consent of publication}

Not applicable.

\section{Authors' contributions}

All authors contributed to the study conception and design. Material preparation, data collection and analysis were performed by MW, SL, MS and TV. The first draft of the manuscript was written by MW and SL, and MS, TV, $\mathrm{MV}$ and LV commented on previous versions of the manuscript. The authors read and approved the final manuscript.

\section{Funding}

The data collection of The Turku Elderly Study was financially supported by ERVA funding of the city of Turku/Welfare Division, Red Feather Campaign of the Nordic Lions Club, and King Gustaf V:s and Queen Victorias Freemasons' Foundation. Funders had no role in the design, execution, analyses, and interpretation of the data in this study.

\section{Availability of data and materials}

The datasets used and/or analysed during the current study are available from the corresponding author on reasonable request.

\section{Ethics approval and consent to participate}

The study was conducted according to the Declaration of Helsinki. The protocol of the Turku Elderly Study was approved by the City of Turku ethical committee on health care and the Ethical Committee of the Hospital District of Southwest Finland. A written informed consent was obtained from all participants.

\section{Competing interests}

The authors declare that they have no competing interests.

\section{Author details}

Faculty of Medicine, Department of Geriatrics, University of Turku, Turku City Hospital, Kunnallissairaalantie 20, Fl-20700 Turku, Finland. ${ }^{2}$ City of Turku, Welfare Division, Turku, Finland. ${ }^{3}$ Joint Authority for Päijät-Häme Health and Social Care, Elderly Care and Rehabilitation, Salpausselkä Rehabilitation Hospital, Lahti, Finland. ${ }^{4}$ Faculty of Medicine, Unit of Family Medicine, University of Turku, Turku, Finland. ${ }^{5}$ Institute of Clinical Medicine, Biostatistics, University of Turku, Turku, Finland. ${ }^{6}$ Division of clinical geriatrics, NVS, Karolinska Institutet and Department of Geriatrics Karolinska University Hospital, Huddinge, Stockholm, Sweden.

Received: 14 October 2019 Accepted: 12 March 2020

Published online: 30 March 2020

\section{References}

1. Stanojevic Jerkovic O, Sauliune S, Šaumskas L, Birt C, Kersnik J. Determinants of self-rated health in elderly populations in urban areas of Slovenia, Lithuania and UK: findings of the EURO-URHIS 2 survey. Eur J Pub Health. 2017;27(suppl_2):74-9.

2. DeSalvo KB, Bloser N, Reynolds H, He J, Muntner P. Mortality prediction with a single general self-rated health question. J Gen Intern Med. 2006;21:26775 .

3. Jylhä M. What is self-rated health and why does it predict mortality? Towards a unified conceptual model. Soc Sci Med. 2009:69:307-16.

4. Benyamini Y. Why does self-rated health predict mortality? An update on current knowledge and a research agenda for psychologists. Psychol Health. 2011;26:1407-13.

5. Sternhagen Nielsen AB, Siersma V, Conradsen Hiort L, Drivsholm T, Kreiner S, Hollnagel $\mathrm{H}$. Self-rated general health among 40-year old Danes and its association with all-cause mortality at 10, 20, and 29 years' follow-up. Scand J Public Health. 2008:36:3-11.

6. DeSalvo KB, Muntner P. Discordance between physician and patient selfrated health and all-cause mortality. Ochsner J. 2011:11:232-40.

7. Puvill T, Linderberg J, Slaets JPJ, de Graen AJM, Westerdorp RGJ. How is change in physical health status reflected by reports of nurses and older people themselves? J Gerontol Ser A Biol Sci Med Sci. 2016;72:579-85.

8. Benyamini Y, Blumstein T, Lusky A, Modan B. Gender differences in the selfrated health-mortality association: is it poorer self-rated health that predicts mortality or excellent self-rated health that predicts survival? Gerontologist. 2003;43:396-405 discussion 372-5.

9. Lyyra T-M, Heikkinen E, Lyyra A-L, Jylhä M. Self-rated health and mortality: could performance-based measures of health and functioning explain the association? Arch Gerontol Geriatr. 2006;42:277-88.

10. Lyyra T-M, Leskinen $E$, Jylhä $M$, Heikkinen E. Self-rated health and mortality in older men and women: a time-dependent covariate analysis. Arch Gerontol Geriatr. 2009:48:14-8.

11. Murata C, Kondo T, Takakoshi K, Tatsua H, Toyoshima H. Determinants of self-rated health: could health status explain the association between selfrated health and mortality? Arch Gerontol Geriatr. 2006;43:369-80

12. Upmeier E, Vire J, Korhonen MJ, Wuorela M, Viitanen M, Isoaho H, et al. Cardiovascular risk profile and use of statins at the age of 70 years: a comparison of two Finnish birth cohorts born 20 years apart. Age Ageing 2016;45:84-90

13. Martin FC, Brighton P. Frailty: different tools for different purposes? Age Ageing. 2008;37:129-31.

14. Mitnitski A, Song X, Skoog I, Broe GA, Cox JL, Grunfeld E, et al. Relative fitness and frailty of elderly men and women in developed countries and their relationship with mortality. J Am Geriatr Soc. 2005;53:2184-9.

15. Rockwood K, Mitnitski A. Frailty in relation to the accumulation of deficits. J Gerontol A Biol A Sci Med Sci. 2007:62A:722-7.

16. Rockwood K, Howlett SE, MacKnight C, Beattie BL, Bergman H, Hébert R, et al. Prevalence, attributes, and outcomes of fitness and frailty in community-dwelling older adults: report from the Canadian study of health and aging. J Gerontol A Biol Sci Med Sci. 2004;59A:1310-7.

17. Rockwood K, Andrew M, Minitski A. A comparison of two approaches to measuring frailty in elderly people. J Gerontol A Biol Sci Med Sci. 2007;62A: 738-43.

18. Song X, Mitnitski A, Rockwood K. Prevalence and 10-year outcomes of frailty in older adults in relation to deficit accumulation. J Am Geriatr Soc. 2010:58: $681-7$. 
19. Folstein MF, Folstein SE, McHugh PR. 'mini-mental state'. A practical method for grading the cognitive status of patients for the clinician. J Psychiatr Res. 1975;12:189-98.

20. O'Bryant SE, Humphreys JD, Smith GE, Ivnik RJ, Graff-Radford NR, Petersen $\mathrm{RC}$, et al. Detecting dementia with the mini-mental state examination (MMSE) in highly educated individuals. Arch Neurol. 2008;65:963-7.

21. Spering CC, Hobson V, Lucas JA, Menon CV, Hall JR, O'Bryant SE. Diagnostic accuracy of the MMSE in detecting probable and possible Alzheimer's disease in ethnically diverse highly educated individuals: an analysis of the NACC database. J Gerontol. 2012;67:890-6.

22. Charlson ME, Pompei P, Ales KL, MacKenzie CR. A new method of classifying prognostic comorbidity in longitudinal studies: development and validation. J Chronic Dis. 1987:40:373-83.

23. Sundararajan V, Henderson T, Perry C, Muggivan A, Quan H, Ghali WA. New ICD-10 version of the Charlson comorbidity index predicted in-hospital mortality. J Clin Epidemiol. 2004;57:1288-94.

24. Schnittker J, Bacak V. The increasing predictive validity of self-rated health. PLoS One. 2014;9:e84933.

25. Shen C, Schooling CM, Chan WM, Zhou JX, Johnston JM, Lee SY, et al. Selfrated health and mortality in a prospective Chinese elderly cohort study in Hong Kong. Prev Med. 2014;67:112-8.

26. Falk H, Skoog I, Johansson L, Guerchet M, Mayston R, Hörder H, et al. Selfrated health and its association with mortality in older adults in China, India and Latin America - a 10/66 dementia research group study. Age Ageing. 2017:46:932-9.

27. Kusumastuti S, Gerds TA, Lund R, Mortensen EL, Westendorp RGJ. Discrimination ability of comorbidity, frailty, and subjective health to predict mortality in community-dwelling older people: population based prospective study. Eur J Intern Med. 2017:42:29-38.

28. DeSalvo KB, Fisher WP, Tran K, Bloser N, Merril W, Peabody J. Assessing measurement properties of two single-item general health measures. Qual Life Res. 2006;15:191-201.

29. Gordon EH, Peel NM, Samanta M, Theou O, Howlett SE, Hubbard RE. Sex differences in frailty: a systematic review and meta-analyses. Exp Gerontol. 2017:89:30-40

30. Vuorisalmi M, Lintonen T, Jylhä M. Global self-rated health data from a longitudinal study predicted mortality better than comparative self-rated health in old age. J Clin Epidemiol. 2005;58:680-7.

\section{Publisher's Note}

Springer Nature remains neutral with regard to jurisdictional claims in published maps and institutional affiliations.

Ready to submit your research? Choose BMC and benefit from:

- fast, convenient online submission

- thorough peer review by experienced researchers in your field

- rapid publication on acceptance

- support for research data, including large and complex data types

- gold Open Access which fosters wider collaboration and increased citations

- maximum visibility for your research: over $100 \mathrm{M}$ website views per year

At $\mathrm{BMC}$, research is always in progress.

Learn more biomedcentral.com/submissions 